RU Проектирование электронного курса по иностранному языку в системе дистанционного обучения "Moodle" в образовательных организациях МВД России

\author{
Калашникова С. В., Пестова Е. В.
}

\begin{abstract}
Аннотация. Цель исследования - проектирование учебного курса в системе дистанционного обучения “Moodle” в образовательных организациях МВД России. В статье определены особенности и функции системы дистанционного обучения “Moodle”. Научная новизна исследования заключается в спроектированном авторами электронном курсе «Иностранный язык (совершенствование английского языка)», представляющем совокупность взаимосвязанных элементов, используемых на аудиторных и внеаудиторных занятиях. На примере авторского курса анализируется эффективность организации образовательного процесса и актуальность методического сопровождения дисциплины «Иностранный язык». Полученные в ходе исследования результаты свидетельствуют о повышении качества знаний по иностранному языку у обучающихся посредством дистанционного обучения.
\end{abstract}

\title{
EN Designing Moodle Course on Foreign Language for Educational Institutions of the Ministry of Internal Affairs of the Russian Federation
}

\author{
Kalashnikova S. V., Pestova E. V.
}

Abstract. The research objective is as follows: to develop a Moodle course for educational institutions of the Ministry of Internal Affairs of the Russian Federation. The authors describe the functioning of the Moodle system. Scientific originality of the study lies in the fact that the authors present an electronic English language course containing a set of interrelated tasks for classroom and independent work. By the example of the authorial course, the paper analyses efficiency of educational process organization and relevance of methodological provision of the "Foreign Language" discipline. The experiment results allow concluding that the authorial electronic course helps to improve students' foreign-language skills.

\section{Введение}

Актуальность исследования обусловлена необходимостью активного использования системы дистанционного обучения “Moodle” в процессе обучения иностранному языку сотрудников органов внутренних дел в образовательных организациях МВД в связи с тем, что электронные курсы способствуют достижению результата в соответствии с поставленными целями и задачами.

Отличительной чертой XX века в области образования стало возникновение новых видов образовательной деятельности, новых образовательных организаций, новых образовательных услуг. Появление дистанционного обучения связано с потребностью получения индивидуализированного образования, которое базируется на использовании информационно-коммуникационных технологий. Дистанционное обучение, предусматривающее взаимодействие преподавателя с обучающимися, зависит от уровня подготовки преподавательского состава к использованию ресурсов дистанционного обучения.

Проблемы дистанционного обучения широко освещаются в научно-педагогической литературе. По мнению Б. А. Бенедиктова [2], Е. С. Полат [9], которые разрабатывали концепцию дистанционного обучения, следует учитывать дидактические свойства и функции компьютерных технологий и обеспечить целенаправленную и последовательную подготовку педагогических кадров к организации процесса обучения в дистанционном формате, принимая во внимание особенности методики преподавания конкретной дисциплины. 
Обучение иностранному языку наиболее эффективно происходит в реальном образовательном процессе, но с вынужденным переходом на дистанционное обучение возникла необходимость организации эффективного процесса, направленного на совершенствование коммуникативных навыков.

Для достижения поставленной цели необходимо решить следующие задачи:

- раскрыть понятие «дистанционное обучение» в современном образовании;

- изучить особенности и функции системы дистанционного обучения “Moodle” в образовательном процессе;

- спроектировать электронный курс по иностранному языку в системе дистанционного обучения "Moodle”.

В качестве основных методов исследования используются изучение и теоретический анализ литературы по методике преподавания иностранного языка в высшей школе; анализ ресурсов системы дистанционного обучения “Moodle”; эмпирический метод.

Теоретической базой исследования стали научные работы Е. С. Полат, В. И. Солдаткиной [10], посвященные системе дистанционного образования; Б. А. Бенедиктова [2], Н. Д. Гальсковой [3], которые рассматривали особенности обучения иностранным языкам.

Практическая значимость исследования заключается в том, что результаты внедрения и использования ресурсов системы дистанционного обучения “Moodle” при обучении иностранному языку могут быть использованы в образовательном процессе Барнаульского юридического института МВД России.

\section{Понятие «дистанционное обучение» в современном образовании}

В научной литературе рассматриваются понятия «дистанционное обучение», «электронное обучение» (e-learning - обучение online), «смешанное обучение» (blended learning) [1; 7; 8]. Наличие разнообразных понятий обусловлено применением информационно-коммуникационных технологий, которые успешно внедряются в образовательный процесс, уровнем индивидуализации процесса обучения, степенью информативности изучаемого учебного материала, степенью взаимодействия с обучающимися.

Дистанционное обучение, возникшее как одна из форм системы образования в XXI веке, не может заменить заочное обучение и тем более традиционное обучение. Основной характеристикой дистанционного обучения является удаленное взаимодействие между обучающимися и преподавателем. Образовательный процесс построен таким образом, что обучающиеся самостоятельно определяют пути усвоения содержания дисциплины. Количество образовательных траекторий значительно больше, чем в традиционном обучении, что обуславливает индивидуализацию образования [12].

Электронное обучение (e-learning) ориентировано на сотрудничество обучающихся с преподавателем. В процессе обучения используются интернет-ресурсы, онлайн-курсы, коллекции образовательных ресурсов, мобильные ресурсы. Обучение осуществляется с преподавателем и без него. Важное значение приобретает информационное наполнение изучаемых курсов, методическое сопровождение обучения.

Термин “blended learning” (смешанное обучение) обозначает процесс, который сочетает возможность коммуникации в реальном и виртуальном пространстве посредством мультимедийного и цифрового оборудования [6]. Возможности смешанного обучения позволяют преподавателю реализовать собственные профессиональные интересы и создать языковую среду на аудиторных занятиях. Смешанное обучение предполагает использование печатных изданий и интернет-ресурсов.

Учитывая разносторонние определения понятий «дистанционное обучение», «электронное обучение», «смешанное обучение», следует отметить общие черты, характерные для указанных форм образования: использование информационно-компьютерных технологий; интерактивность - взаимодействие преподавателя и обучающихся в online или удаленном пространстве; значительный объем самостоятельной деятельности обучающихся; наличие системы контроля усвоения иностранного языка.

Несмотря на наличие общих черт, названные формы обучения, по мнению ученых-исследователей [5; 7; 8], имеют значительные недостатки, а именно: содержание обучающих программ не соответствует уровню обучающихся, значительный информационный объем, несоответствие образовательным целям, отсутствие системы контроля и оценивания.

Таким образом, дистанционное обучение является одной из перспективных форм современного образования, которые содействуют интенсификации образовательного процесса посредством использования информационно-коммуникационных технологий и формированию у обучающихся умения самостоятельно приобретать знания под контролем и без преподавателя.

\section{Изучение особенностей и функций системы дистанционного обучения “Moodle” в образовательном процессе}

Система управления обучением “Learning Management System” (LMS-system) создана как образовательная платформа, которая позволяет не только создать информационно-образовательную среду в образовательной организации в целом и по дисциплине в частности, но и управлять ею [4]. Данная система лишена обозначенных недостатков и направлена на обучение, взаимодействие преподавателя с обучающимися в пределах одного сайта.

Особенности платформы “Moodle” заключаются в следующем:

- наличие гипертекстовых ссылок, что позволяет обучающимся иметь расширенный доступ к сети Интернет;

- гибкость (возможность управления содержанием); 
- доступность (отсутствие необходимости изучать языки программирования);

- возможность индивидуального оценивания и контроля.

Система дистанционного обучения “Moodle” является инструментом организации образовательного процесса, направленного на овладение иностранным языком, и выполняет следующие функции:

- образовательная, которая заключается в актуализации умений и навыков иностранного языка на известном лексико-грамматическом материале; активизации употребления лексических единиц на основе условно-коммуникативных заданий;

- воспитательная, направленная на формирование ценностных ориентаций обучающихся, осуществление связи теоретических знаний с практикой путем решения проблемных вопросов; воспитание преданности к профессии;

- познавательная, способствующая речемыслительной деятельности обучающихся, развитию познавательной активности и самостоятельности; индивидуализации процесса обучения с помощью различных заданий.

Таким образом, система дистанционного обучения “Moodle” обеспечивает эффективный педагогический процесс и способствует формированию у обучающихся коммуникативной компетенции, которая потребуется при осуществлении профессиональной деятельности.

\section{Проектирование электронного курса по иностранному языку в системе дистанционного обучения “Moodle”}

Главной целью обучения иностранному языку в образовательных организациях МВД России является формирование умений и навыков общения в профессионально ориентированных ситуациях, а также последовательное совершенствование профессиональных знаний, умений и навыков. Для практического овладения иностранным языком обучающиеся должны понимать речь собеседника, читать специальную литературу, участвовать в устном общении, заполнять специальную документацию. Система дистанционного обучения “Moodle” предлагает оптимальные условия для эффективного усвоения теоретического и практического материала, осуществления последовательных организационных действий по усвоению учебного материала [5].

На примере разработанного в системе дистанционного обучения “Moodle” авторского курса «Иностранный язык (совершенствование английского языка)» были определены эффективные способы обучения коммуникации на иностранном языке. Авторский курс был разработан для сотрудников органов внутренних дел, обеспечивающих охрану общественного порядка при проведении второго этапа Кубка мира - 2021 по гребле и каноэ, проводимого в г. Барнауле.

Цель данного курса - обучение иностранному языку на основе профессионально ориентированного содержания. При проектировании курса «Иностранный язык (совершенствование английского языка)» нами была учтена система действий, реализуемая в рамках преподавания дисциплины.

1. Методическое обеспечение курса: разработанные и изданные авторские пособия и научные издания по дисциплине «Иностранный язык»; пособия, в которые включены методические рекомендации к проведению самостоятельной работы. Пособия отражают языковой материал английского языка, реализуют речевые действия по решению профессиональных коммуникативных задач.

2. Структурирование языкового материала способствует усвоению предъявляемого материала. При проектировании курса учитывались принципы «от простого к сложному», «от общего к частному». Курс «Иностранный язык (совершенствование английского языка)» может быть представлен следующей структурой. Аудиторные занятия: печатные учебные пособия и научные издания; раздаточный материал; видео- и аудиофрагменты. Занятия в системе “Moodle”: презентации, электронные пособия, аудио- и видеофайлы, форум, чат и т.д. Данная структура определяет следующие виды учебной деятельности. Аудиторные занятия: аудирование, говорение, чтение, письмо. Дистанционные занятия: тренажеры, проектные работы, проблемные вопросы, речевые упражнения и т.д.

3. Логическое построение изложения языкового и речевого материала. Практический материал включает взаимосвязанные элементы иностранного языка. Каждый следующий элемент логично следует за предыдущим и обеспечивает взаимопроникновение в содержание курса.

4. Сочетание практического и теоретического материала. В созданном курсе теоретический материал представлен лекциями по грамматике английского языка. На практических занятиях предъявляемый теоретический материал подкрепляется конкретными лексико-грамматическими и условно-речевыми упражнениями и заданиями, отрабатывается в различных видах учебной деятельности.

5. Дифференцированный подход к формированию практических заданий. Формирование практических заданий ограничивается потребностями обучающихся (принцип коммуникативной направленности); целью и задачами обучения иностранному языку; спецификой этапа обучения; особенностями восприятия и запоминания языкового материала [Там же].

6. Разработка домашних заданий, развивающих речевые навыки и творчество. Домашние задания могут быть эффективным средством обучения иноязычной речи, если они содержат актуальный языковой материал для развития речевых навыков и умений. При выборе заданий прослеживаются два направления: коммуникативное и лингвистическое. Отбор лексического материала должен сводиться не только к коммуникативному принципу, но и соответствовать лингвистическим критериям, среди которых следует выделить тематический принцип, т.е. задания должны актуализировать лексическое содержание курса [11]. 
7. Технология проведения итоговой аттестации: тест, определяющий знания обучающихся по грамматике; практическое задание, позволяющее обучающимся применить полученные знания и умения.

Обозначенные действия позволяют ускорить процесс формирования устойчивых коммуникативных навыков, высвободить время на творческую, самостоятельную деятельность обучающихся, а значит, повысить эффективность образовательного процесса в целом.

Курс «Иностранный язык (совершенствование английского языка)» имеет целью совершенствование иноязычной речи сотрудников органов внутренних дел, которые обучаются на факультете повышения квалификации. Используя ресурсы системы дистанционного обучения “Moodle”, авторский курс включает следующие элементы: «Глоссарий», «Лекция», «Урок», «Задания для самоподготовки», «Форум/Чат», «Тест». В процессе обучения данные элементы применяются в зависимости от цели и задач конкретного практического занятия.

«Глоссарий», содержащий лексику и термины по основным темам курса, представляет мультимедийный словарь, снабженный гиперссылками, позволяющими определить толкование лексических единиц и их использование в контексте изучаемых тем.

«Лекция» - элемент курса, который допускает чтение теоретического грамматического материала на русском языке. Объясняя употребление грамматических конструкций, целесообразно придерживаться дифференцируемого подхода. Предъявление грамматических явлений ограничивается их использованием в процессе профессиональной коммуникации. В ходе лекции используются презентации, таблицы, схемы и другая наглядность. Грамматический материал предъявляется в виде лекции-беседы, которая активизирует логическое мышление обучающихся, предполагает обратную связь. Обратная связь возможна в таких элементах курса, как «Форум/Чат». В процессе изложения материала обучающиеся могут задавать уточняющие вопросы, что сказывается на прочности запоминания учебного материала.

«Урок» как элемент курса способствует организации процесса обучения. Данный элемент разбит на последовательные этапы, которые взаимодополняют друг друга. Первый этап - чтение и обсуждение текста предполагает чтение без словаря и беспереводной контроль (вопросы, микроситуации), чтение со словарем и контроль понимания путем перевода.

Второй этап предусматривает устную работу по теме. Тематический план курса включает следующие темы: «Ориентирование в городе», «Достопримечательности, транспортная и социальная инфраструктура, объекты проведения спортивных мероприятий», «Охрана общественного порядка», «Работа полиции». Курс рассчитан на 72 часа, количество тем ограничено временем обучения и потребностями обучающихся. На данном этапе используются различные виды учебной деятельности:

- тренинги (отработка действий полицейского при решении возникающих задач). Например: 1. Укажите иностранным гостям на нарушение правил поведения в общественном месте. Попросите их пройти в полицейский участок;

- проблемные ситуации (поиск решений и нахождение оптимальных образцов речи). Например: 1. Иностранный гость нарушает правила дорожного движения. Напомните ему о правилах дорожного движения, о мере наказания за совершенный проступок.

Третий этап - выполнение письменной работы (оформление протокола задержания, заполнение бланка рапорта о преступлении и др.). Образцы письменных работ согласуются с профильными кафедрами, имеют целью не только закрепление орфографических навыков, но и отработку навыков устной речи на основе письменных заданий.

Элемент курса «Задания для самоподготовки» содержит учебный материал для самостоятельной работы, который индивидуализирует деятельность обучающихся. Элемент снабжен аудио- и видеофайлами. Тексты для аудирования направлены на восприятие лексических и грамматических конструкций в речи. Контроль понимания осуществляется путем постановки вопросов после прослушивания. Обучающиеся имеют возможность вернуться к изученному материалу, многократно его проработать, запомнить речевые образцы, клишированные фразы, которые помогут установить контакт с людьми при выполнении профессиональных задач.

Элемент «Форум/Чат» является действенным инструментом взаимодействия преподавателя с обучающимися, обучающихся друг с другом. Преподаватель оценивает деятельность обучающихся, определяет время сдачи выполненных работ для оценивания, комментирует ответы.

Для входного тестирования и итоговой аттестации используется элемент курса «Тест». Платформа “Moodle” позволяет создавать тесты с использованием вопросов различных видов: закрытая форма (многовариантный выбор); открытая форма (вставка пропущенных слов, фраз); задания на соответствие (подбор варианта к заданному понятию, определению); задания на установление верной последовательности (логика следования понятий, действий) и другие. Система тестирования осуществляет контроль знаний обучающихся, выполняющих практические задания, и обеспечивает интерактивную связь с последующей коррекцией. При создании теста следует обращать внимание на количество вопросов, временные ограничения, количество попыток, возможность увидеть результаты в баллах. Результаты тестирования хранятся в ведомости, преподаватель отслеживает деятельность обучающихся, своевременность посещения и активность в системе дистанционного обучения “Moodle”.

Эффективность организации авторского курса была доказана с помощью метода эмпирического исследования. В опросе приняли участие 36 слушателей факультета повышения квалификации, которые дистанционно обучались по дисциплине «Иностранный язык». Все опрошенные слушатели ранее изучали иностранный (английский) язык. До начала обучения считали необходимым повышение уровня владения иностранным 
языком только 28\%. Качество знаний по результатам входного контроля составило 3,8 балла. По завершении курса обучения слушатели проходили итоговую аттестацию, средний балл которой составил 4,4 балла. 93\% опрошенных отметили, что знания, полученные при обучении, достаточны или в основном достаточны для успешного выполнения служебных обязанностей.

В ходе анкетирования слушатели оценили преимущества дистанционного обучения (многовариантный выбор). Результаты представлены в Таблице 1.

Таблица 1. Преимущества дистанционного обучения

\begin{tabular}{|l|c|}
\hline $\begin{array}{l}\text { Легкость обновления содержания и возможность архивации изученного материала: } \\
\text { любой учебный материал доступен для скачивания }\end{array}$ & $11 \%$ \\
\hline Технологичность процесса обучения (использование информационных технологий) & $17 \%$ \\
\hline Обучение в комфортной обстановке & $19 \%$ \\
\hline Гибкость образовательного процесса & $20 \%$ \\
\hline Возможность совмещать работу с обучением & $43 \%$ \\
\hline
\end{tabular}

Однако в процессе обучения часть слушателей испытывали трудности в первую очередь в связи с недостаточностью личного взаимодействия с преподавателем (18\%) и с невозможностью обучаться в образовательной организации (13\%).

Обучающимся было предложено оценить электронный курс «Иностранный язык (совершенствование английского языка)», размещенный в СДо “Moodle”, с учетом информативности, ясности, структурированности, иллюстративности представленного учебного материала по шкале от 1 до 5. Результат опроса показал следующие результаты: 77\% оценили качество курса на «5», 19\% - на «4», 4\% - на «3».

На практике логическое построение электронного курса сопровождается заблаговременным размещением графика прохождения дисциплины, который включает порядок, сроки освоения лексического и грамматического материала, практические задания для текущего контроля. Обучающиеся получают доступ к учебному материалу в удобное для них время, что способствует рациональному распределению самостоятельной работы по изучению содержания курса. Преподаватель должен учитывать факт выполнения обучающимися служебных обязанностей. Доступность размещенного материала положительно оценили 59\% опрошенных, а 85\% опрошенных отметили уменьшение объема бумажной работы.

Проведенное исследование подтвердило практическую значимость использования дистанционного обучения в образовательном процессе. Применение авторского курса «Иностранный язык (совершенствование английского языка)» способствует повышению качества подготовки сотрудников органов внутренних дел, развитию коммуникативной компетенции и способности к самостоятельной деятельности.

\section{Заключение}

В результате исследования рассмотрены особенности и установлены функции системы дистанционного обучения “Moodle”, а именно образовательная, воспитательная, познавательная. К преимуществам дистанционного обучения относятся гибкость, доступность, интерактивность, возможность индивидуального оценивания и контроля.

Ресурсы дистанционного обучения на платформе “Moodle” были использованы при проектировании авторского курса «Иностранный язык (совершенствование английского языка)». Элементы курса «Глоссарий», «Лекция», «Урок», «Задания для самоподготовки», «Форум/Чат», «Тест» позволяют представить язык как средство общения, а не фокусироваться только на грамматических и лексических явлениях. Обучающиеся приобретают навыки коммуникации, которые необходимы для осуществления правоохранительной деятельности.

В результате внедрения информационно-коммуникационных технологий в процесс обучения иностранному языку обучающиеся развивают навыки самостоятельной работы, активно включаются в процесс приобретения профессиональных знаний и активизации творческих способностей.

Перспективы дальнейшего исследования заключаются в изучении эффективности системы видеоконференцсвязи “TrueConf” и системы проведения вебинаров “BigBlueButton”, интегрированных в Электронную информационно-образовательную среду Барнаульского юридического института МВД России, а также в разработке методических рекомендаций по использованию дистанционных технологий в процессе обучения иностранному языку.

\section{Источники | References}

1. Андреев А. А., Солдаткин В. И. Дистанционное обучение и дистанционные образовательные технологии // Cloud of Science. 2013. № 1. С. 14-20.

2. Бенедиктов Б. А. Психология овладения иностранным языком. Мн.: Вышэйшая школа, 1974. 336 с.

3. Гальскова Н. Д. Современная методика обучения иностранным языкам как наука: проблемы и перспективы [Электронный ресурс]. URL: https://evestnik-mgou.ru/ru/Issues/View/11 (дата обращения: 12.05.2021). 
4. Желтобрюх А. В., Дакуева В. М., Сошин А. А., Ковалев Д. В. Использование в учебном процессе системы дистанционного обучения “Moodle” при реализации программ профессионального обучения // Педагогика. Вопросы теории и практики. 2017. № 3 (7) С. 39-41.

5. Кисарин А. С. Дистанционное обучение английскому языку: достоинства и недостатки [Электронный ресурс]. URL: https://scipress.ru/fam/articles/distantsionnoe-obuchenie-anglijskomu-yazyku-dostoinstva-i-nedostatki.html (дата обращения: 14.04.2021).

6. Любимова Н. В., Горожанов А. И. Технология «смешанного» обучения иностранным языкам: перспективы и проблемы // Вестник Московского государственного лингвистического университета. 2011. № 609. С. 49-58.

7. Михеева С. А., Свит Е. П. Опыт и перспективы использования электронного обучения в образовательной среде педагогического университета // Известия Российского государственного педагогического университета им. А. И. Герцена. 2014. № 168. С. 122-127.

8. Никуличева Н. А. Дистанционное обучение в образовании: организация и реализация. M.: LAP, 2019. 220 с.

9. Полат Е. С. Теория и практика дистанционного обучения: учеб. пособие для студ. высш. пед. учеб. заведений. М.: Академия, 2004. 416 с.

10. Полат Е. С., Бухаркина М. Ю., Моисеева М. В. и др. Теория и практика дистанционного обучения: учеб. пособие. М.: Академия, 2004. 416 с.

11. Худолей Н. В. Методика использования инструментария LMS Moodle для развития навыков коммуникации на иностранном языке у студентов неязыкового вуза // Филологические науки. Вопросы теории и практики. 2019. т. 12. Вып. 10. С. 385-390.

12. Шатуновский В. Л., Шатуновская Е. А. Ещё раз о дистанционном обучении (организация и обеспечение дистанционного обучения) // Вестник науки и образования. 2020. № 9 (87). Ч. 1. С. 53-56.

\section{Информация об авторах | Author information}

RU Калашникова Светлана Викторовна ${ }^{1}$, к. пед. н., доц.

Пестова Елена Владимировна ${ }^{2}$, к. пед. н., доц.

1,2 Барнаульский юридический институт Министерства внутренних дел Российской Федерации

EN Kalashnikova Svetlana Viktorovna ${ }^{1}, \mathrm{PhD}$

Pestova Elena Vladimirovna ${ }^{2}, \mathrm{PhD}$

${ }^{1,2}$ Barnaul Law Institute of the Ministry of Internal Affairs of the Russian Federation

${ }^{1}$ kalash-sv@mail.ru, ${ }^{2}$ elena.pestova.72@list.ru

\section{Информация о статье | About this article}

Дата поступления рукописи (received): 17.06.2021; опубликовано (published): 15.09.2021.

Ключевые слова (keywords): дистанционное обучение; электронный курс; обучение иностранному языку; платформа "Moodle"; образовательные организации МВД России; distant learning; electronic course; foreign language teaching; Moodle platform; educational institutions of the Ministry of Internal Affairs of the Russian Federation. 